\title{
Synthesis, Characterization and Study of Effect of Irradiation on Electronic Properties of Polyaniline Composite with Metal Complex of Co (III)
}

\author{
Waseem Naqash $^{a}$, Kowsar Majid ${ }^{a}$ \\ ${ }^{a}$ Department of Chemistry, National Institute of Technology Srinagar-190 006, J\& K, India
}

Received: August 17, 2015; Revised: August 18, 2015

\begin{abstract}
The present work reports the synthesis of PANI composite with hexamminecobalt(III) chloride metal complex as dopant via in situ oxidative polymerization by ammonium persulphate in non-aqueous DMSO medium. The dopant metal complex has been synthesized by known method and characterized by using FTIR, XRD and SEM analysis. The synthesized PANI/[Co( $\left.\left(\mathrm{NH}_{3}\right)_{6}\right] \mathrm{Cl}_{3}$ composite was characterized by FTIR, XRD, UV-Vis and SEM techniques. FTIR of PANI composite showed its successful synthesis with the presence of some dopant peaks in its FTIR spectrum. XRD spectra of composite revealed its crystalline nature having almost same spectra as that of dopant metal complex with slight shift in the position of peaks. Electrical measurement of the composite was made using four probe conductivity meter and the thermal studies have been done by thermal gravimetric (TG) technique. The results showed improvement in the thermal stability of PANI composite together with increase in its conductance, thereby making it a possible future material for high temperature application purposes. Electronic properties of the composite were investigated using UV-Vis spectroscopy which revealed decrease in the energy band gap of the composite on irradiation. This is attributed to the distortion of polymer chains on exposure to radiations, which results in decrease in conjugation and hence increases in band gap energy.
\end{abstract}

Keywords: polyaniline (PANI), PANI composite, dopant metal complex

\section{Introduction}

Conducting polymers are organic polymers capable of conducting electricity that has been studied extensively and are called as the materials of $21^{\text {st }}$ century. The conducting polymers which have been investigated include polyaniline (PANI), polypyrole (PPY), polythiophene (PTH), etc. New class of materials are obtained with the controlled addition of one of the components in these polymers as a dopant, a process commonly referred as doping as analogous to semiconducting technology. The reduction in the size of the dopant to nano level results in dramatic change in electrical, thermal, electronic, magnetic, optical, and other properties of polymers. In this direction polyaniline (PANI) has been studied and investigated extensively with respect to facile synthesis by chemical and electrochemical process, environmental stability, low cost, high conductivity, solubility, and chemical sensitivity ${ }^{1}$. It has drawn considerable attention for its wide application in microelectronic devices, photodiodes, sensors, light weight batteries, solar cells, electrochemical capacitors, corrosion capacitors, corrosion inhibitors, drug delivery and electromagnetic interference shielding materials ${ }^{2-4}$. Various composites of PANI with different fillers or dopants like $\mathrm{MoO}_{3}, \mathrm{MnO}_{3}, \mathrm{WO}_{3}, \mathrm{TiO}_{2}$, $\mathrm{BF}_{3}, \mathrm{CNTS}$ etc. have been synthesized, characterized and explored for various possible applications ${ }^{5-9}$. In the same direction some of the transition metals and their complexes containing polymers have also been prepared and studied ${ }^{10}$ and are interesting systems under consideration in various

*e-mail: kowsarmajid@rediffmail.com fields such as organic electronics, where PANI/metal hetero junctions are employed for electrical transport and rectification ${ }^{11}$, as protective coatings against corrosion of metal surfaces ${ }^{12-14}$, as redox-active catalysts for inducing chemical reactions in coordination chemistry ${ }^{15,16}$, etc. PANI is used as a model polymer for study of the above interactions, because its backbone consists of two basic groups possessing different activity with respect to metal cations, namely the electron-rich benzenoid group and electron-deficient quinoid group $^{17}$. The purpose of using transition metal complexes as fillers in conducting polymer matrices is to impart some desirable properties to conducting polymers. These properties include good thermal stability, good mechanical strength, crystallinity for good processibility, etc. The above mentioned properties coupled with good electrical conductivity make these nanocomposites as exciting materials for different applications. The metal complex copper(bisglycinate) has made composites suitable for high temperature application purposes ${ }^{18}$. The polyaniline and polythiophene composite with rare earth terbium(III) complex possess good thermal stability and fluorescence property which make them possible candidates for their technological applications as luminescent probes or light emitting diode materials ${ }^{19}$. Role of photoadducts using $\mathrm{K}_{4}\left[\mathrm{Fe}(\mathrm{CN})_{6}\right]$ metal complex in improving thermal, electrical and mechanical properties of PANI composite has been recently investigated by our group ${ }^{20}$. The present study involves the synthesis and characterization of PANI composite with a photoactive transition metal complex hexamminecobalt(III) chloride. This complex being photoactive 
undergoes redox decomposition in aqueous solution when irradiated with $254 \mathrm{~nm}$ light with the formation of $\mathrm{Co}^{2+}$ and consumption of $\mathrm{H}^{+}$ions according to zero order kinetics. However when irradiation is carried out in the ligand field bands, release of ammonia occurs with the quantum yield of $5.4 \times 10^{-3}$ at $365 \mathrm{~nm}\left({ }^{1} \mathrm{~A}_{1 \mathrm{~g}} \rightarrow{ }^{1} \mathrm{~T}_{2 \mathrm{~g}}\right.$ band $)$ and $5.2 \times 10^{-4}$ at $472 \mathrm{~nm}\left({ }^{1} \mathrm{~A}_{1 \mathrm{~g}} \rightarrow{ }^{1} \mathrm{~T}_{1 \mathrm{~g}}\right.$ band). The released ammonia ligands can be substituted with some new ligands of our choice. Hence, by irradiating the aqueous solution of the complex at these wavelengths in presence of some other ligand the corresponding photoadducts of the complex can be formed and subsequently doped in PANI polymer to observe the effect of incorporated ligand on the thermal, electrical, mechanical and other properties of polymer. The dopant metal complex which we have taken is having very high thermal stability and is chemically an inert metal complex. Therefore its insertion in polyaniline is expected to increase the thermal stability of the later, besides improvement in some of its other properties. Owing to water soluble nature of dopant metal complex, the synthesis of polyaniline composite has been taken in non-aqueous DMSO medium. The composite prepared has been subjected to various spectroscopic characterizations including surface morphology and also its electrical and thermal properties have been studied for its possible future applications.

\section{Experimental}

\subsection{Materials}

The chemicals used were all of analytical grade. Aniline used was supplied by Merck chemicals and was used after distillation. The other chemicals including $\mathrm{HCl}$, ammonium persulphate, DMSO, cobalt (II) chloride, ammonia, hydrogen peroxide and activated charcoal were supplied by Himedia and were used as received. All solutions were prepared in triple distilled water.

\subsection{Synthesis of Polyaniline (PANI)}

Stable Polyaniline dispersion was prepared in non-aqueous DMSO medium by known method of oxidation of aniline monomer by ammonium persulphate $\left(\mathrm{NH}_{4}\right)_{2} \mathrm{~S}_{2} \mathrm{O}_{8} .1 \mathrm{ml}$ of purified aniline was added to $10 \mathrm{ml}$ of $5 \mathrm{~N}$ solution of $\mathrm{HCl}$ in DMSO and the solution was cooled to a temperature of about $10^{\circ} \mathrm{C}$. The solution of $1.2 \mathrm{~g}$ of ammonium persulphate dissolved in $10 \mathrm{ml}$ of DMSO was then added drop wise to the previous cooled solution for a period of $15 \mathrm{~min}$ with constant stirring. The solution was left for the polymerization of aniline to take place for $12 \mathrm{hr}$ at $10^{\circ} \mathrm{C}$ with occasional stirring. The green colored thick dispersion of PANI obtained in non-aqueous DMSO medium was isolated as precipitate by adding excess of distilled water. The green precipitate was then filtered, washed with acetone repeatedly and dried in an oven at a temperature of about $30^{\circ} \mathrm{C}$.

\subsection{Synthesis of dopant hexamminecobalt(III) chloride $\left[\mathrm{Co}\left(\mathrm{NH}_{3}\right)_{6}\right] \mathrm{Cl}_{3}$}

The synthesis of dopant hexmaminecobalt(III) chloride was carried out by standard reported method ${ }^{21}$. The method involves the treatment of $\mathrm{Co}$ (II) chloride with ammonia and ammonium chloride followed by oxidation with hydrogen peroxide in presence of charcoal as a catalyst. The labile $\left[\mathrm{Co}\left(\mathrm{H}_{2} \mathrm{O}\right)_{6}\right]^{2+}$ aquo-ion formed in solution upon dissolution of $\mathrm{CoCl}_{2}$, reacts with ammonia to give hexamminecobalt(II) $\left[\mathrm{Co}\left(\mathrm{NH}_{3}\right)_{6}\right]^{2+}$ complex, which is successively oxidized by $\mathrm{H}_{2} \mathrm{O}_{2}$ to $\left[\mathrm{Co}(\mathrm{OH})\left(\mathrm{NH}_{3}\right)_{5}\right]^{3+}$. This complex is quite inert but undergoes substitution of coordinated $\mathrm{OH}^{-}$group by $\mathrm{NH}_{3}$ in presence of charcoal as catalyst. The ammonia buffer prevents the $\mathrm{pH}$ increase that would be produced by the release of $\mathrm{OH}^{-}$ions in the substitution step. The overall reaction involved in the synthesis of the complex is as under:

$$
\begin{aligned}
& 2 \mathrm{CoCl}_{2(a q)}+2 \mathrm{NH}_{4} \mathrm{Cl}_{(a q)}+10 \mathrm{NH}_{3(a q)}+ \\
& \mathrm{H}_{2} \mathrm{O}_{2(l)} \rightarrow 2\left[\mathrm{Co}\left(\mathrm{NH}_{3}\right)_{6}\right] \mathrm{Cl}_{3(s)}+2 \mathrm{H}_{2} \mathrm{O}
\end{aligned}
$$

\subsection{Synthesis of $\left[\mathrm{Co}\left(\mathrm{NH}_{3}\right)_{6}\right] \mathrm{Cl}_{3}$ doped PANI composite}

To precooled $1 \mathrm{ml}$ distilled aniline in $10 \mathrm{ml}$ of $5 \mathrm{~N} \mathrm{HCl}$ solution in DMSO, $1.5 \mathrm{~g}$ of synthesized dopant $\left[\mathrm{Co}\left(\mathrm{NH}_{3}\right)_{6}\right] \mathrm{Cl}_{3}$ was added with stirring to form a dispersion as the dopant is insoluble in non-aqueous DMSO medium. To this dispersion $1.2 \mathrm{~g}$ of ammonium persulphate dissolved in $10 \mathrm{ml}$ of DMSO solution was added drop wise at $10^{\circ} \mathrm{C}$ with constant stirring. The mixture was kept as such for about $12 \mathrm{hr}$ at same temperature of about $10^{\circ} \mathrm{C}$ for polymerization reaction and simultaneous interaction between PANI chains and the dopant to take place with occasional stirring. The dispersion formed was isolated as precipitate by adding excess distilled water, filtered and washed with acetone several times. The precipitate was collected over filter paper and dried in an oven at a temperature of about $30-40^{\circ} \mathrm{C}$.

\subsection{Physical measurements}

UV-visible spectra of PANI and that of PANI composite solution in NMP were recorded separately by UV-VIS double beam spectrophotometer (PG Instruments T80). Fourier transform infrared (FTIR) spectra were recorded on Perkin Elmer RX-1 FTIR spectrophotometer using $\mathrm{KBr}$ discs. X-ray diffraction (XRD) was recorded on PW 3050 base diffractometer with $\mathrm{Cu} \mathrm{K} \alpha$ radiations (1.54060 ̊). Surface morphology of the samples was taken on a Hitachi SEM Model S-3600N. Electrical measurement was made using four probe conductivity meter. Thermogravimetric analysis was carried on Universal TA instruments V4.5A in nitrogen atmosphere at a heating rate of $10 \mathrm{~K} \mathrm{~min}^{-1}$. The temperature range was from ambient to $1000^{\circ} \mathrm{C}$. An aluminum pan was used as a reference.

\section{Results and Discussions}

\subsection{UV-VIS characterization}

The UV-VIS spectra of PANI and PANI composite solutions prepared in NMP are shown in Figure 1a, b. The PANI spectrum shows two prominent peaks at $290 \mathrm{~nm}$ and $630 \mathrm{~nm}$. The peaks are attributed to $\pi \rightarrow \pi^{*}$ transition in the benzenoid rings and $\pi \rightarrow \pi^{*}$ transition in quinoid rings of polyaniline ${ }^{22}$. In PANI composite spectrum two peaks at $335 \mathrm{~nm}$ and $665 \mathrm{~nm}$ are observed. The shift in the peaks towards higher wavelength side (red shift) as well 
as increase in the intensity of peak at $665 \mathrm{~nm}$ suggests a decrease in the energy band gap in case of composite and increase in the number of charge carriers which can be due to interaction between dopant metal complex and the polyaniline backbone chains.

Moreover, the synthesized composite was subjected to irradiation for different intervals of time $(0.0 \mathrm{~h}, 0.5 \mathrm{~h}, 1.0 \mathrm{~h}, 1.5 \mathrm{~h})$ to study the effect of radiations on the PANI-metal complex composite (Figure 2). During irradiation, a blue shift in the UV-Vis spectrum of composite was observed with a gradual decrease in the $\lambda_{\text {max }}$, of composite from $635 \mathrm{~nm}$ to $620 \mathrm{~nm}$, after different intervals of time. Due to this blue shift the band gap calculated for each time of irradiation was found to be $1.94,1.96,1.98$, and $1.99 \mathrm{eV}$. The increase in the band gap energy of composite can be attributed to the distortion of PANI chains on irradiation due to the photochemical decomposition of filler which otherwise have held the polymer chains intact as already noted in FTIR. This distortion in PANI chains leads to the decreased conjugation and hence decreases the value of $\lambda \max$ (blue shift) or increases bang gap energy of the composite.

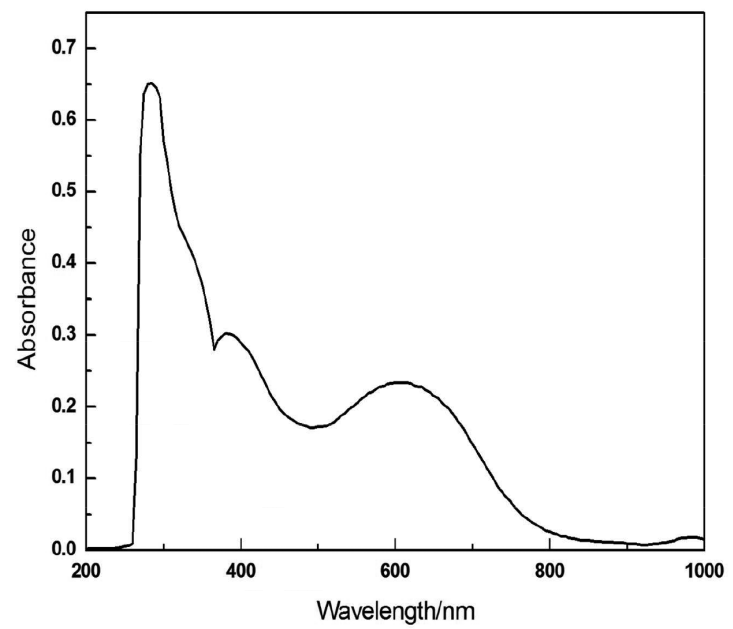

(a)

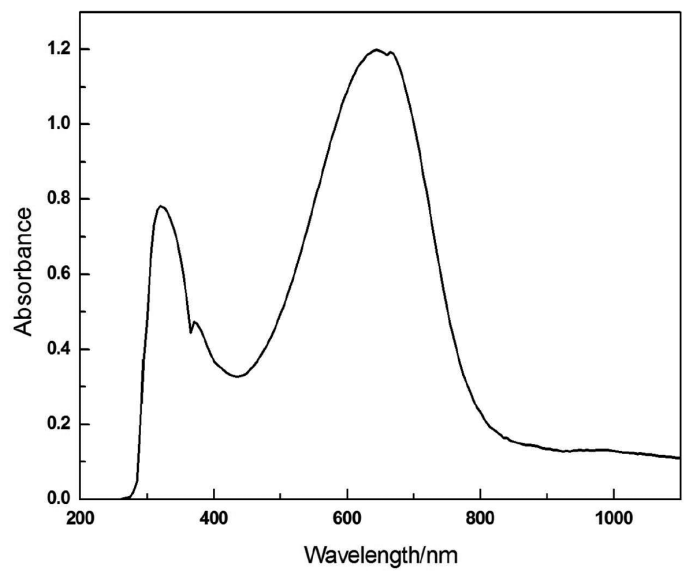

(b)

Figure 1. UV-Visible spectra of (a) pure PANI (b) PANI composite.

\subsection{FTIR characterization}

The FTIR spectra of PANI, dopant metal complex and PANI composite are shown in the Figure 3a-c. PANI shows a hump at $3432 \mathrm{~cm}^{-1}$ due to N-H stretching. The peak at $2923 \mathrm{~cm}^{-1}$ occurs because of aromatic $\mathrm{C}-\mathrm{H}$ bond stretching. The absorption peaks in the region of $1557 \mathrm{~cm}^{-1}$ and $1476 \mathrm{~cm}^{-1}$ corresponds to quinoid and benzenoid ring vibrations respectively. The peaks at 1297 and $1241 \mathrm{~cm}^{-1}$ are probably associated with various $\mathrm{C}-\mathrm{N}$ stretching and bending vibrations. The vibration peak at $1107 \mathrm{~cm}^{-1}$ is attributed to $\mathrm{C}-\mathrm{N}$ double bond. The $\mathrm{C}-\mathrm{H}$ out of plane bending vibration is observed at $797 \mathrm{~cm}^{-1}$. The important peaks in case of dopant $\left[\mathrm{Co}\left(\mathrm{NH}_{3}\right)_{6}\right] \mathrm{Cl}_{3}$ metal complex are observed at $3167 \mathrm{~cm}^{-1}, 1618 \mathrm{~cm}^{-1}, 1327 \mathrm{~cm}^{-1}$ and $830 \mathrm{~cm}^{-1}$. While the first three peaks are assigned to various $\mathrm{N}-\mathrm{H}$ stretching vibrations of complexed $\mathrm{NH}_{3}$, the latter one is because of rocking vibration of $\mathrm{NH}_{3}$ molecule. The FTIR spectrum of PANI composite is very much similar to that of pure PANI, with some shift in the position of peaks and the presence of some new dopant peaks. Vibrational frequencies in PANI composite are observed at $3114 \mathrm{~cm}^{-1}$ for combined

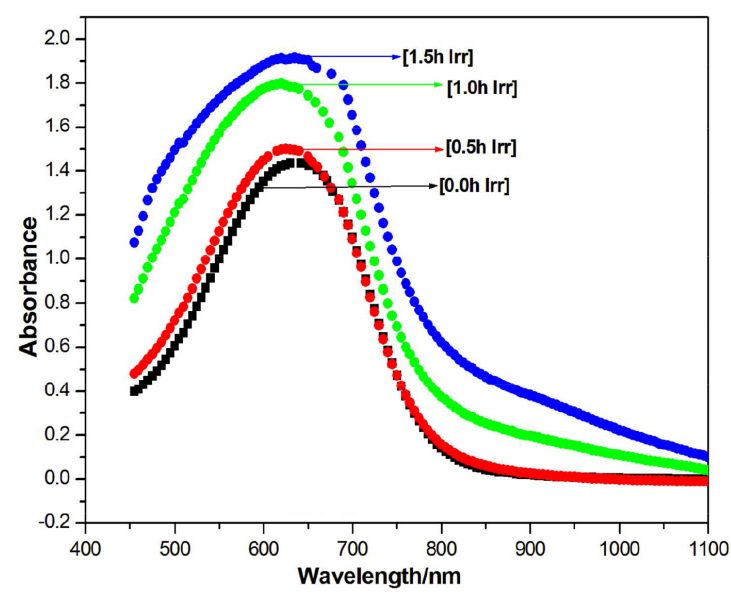

Figure 2. UV-Visible graph of composite after different intervals of irradiation.
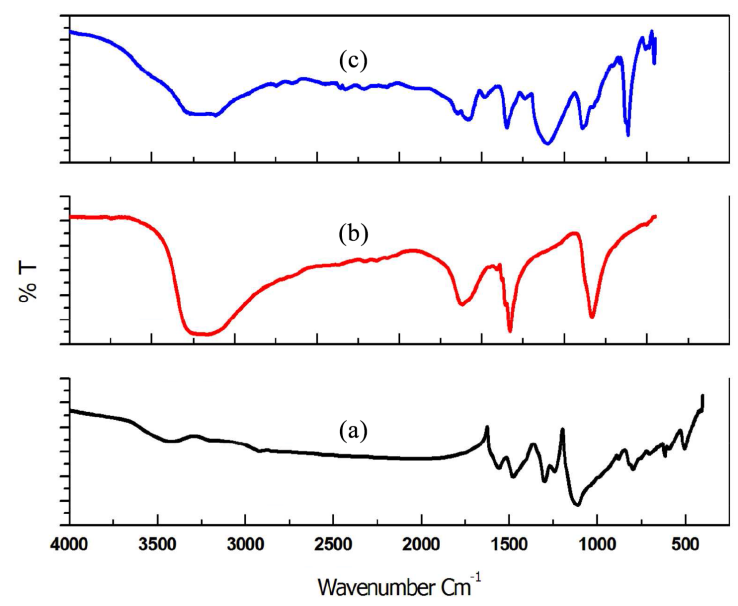

Figure 3. FTIR spectra of (a) pure PANI (b) dopant metal complex (c) composite. 
$\mathrm{N}-\mathrm{H}$ stretching frequencies of complexed $\mathrm{NH}_{3}$ and that of PANI with a decreased intensity. The peak at $1574 \mathrm{~cm}^{-1}$ for quinoid ring vibration shows a significant shift while as the peak at $1481 \mathrm{~cm}^{-1}$ for benzenoid ring stretching remains almost unchanged in the composite. This suggests a possible interaction that might have occurred between the quinoid ring and the dopant metal complex. The peaks at $1238 \mathrm{~cm}^{-1}$ and $1099 \mathrm{~cm}^{-1}$ corresponds to C-N single bond and double bond stretching. The insertion of dopant metal complex into the PANI is evident by the presence of some dopant peaks in the FTIR spectrum of PANI composite with some shift in their position. The peaks observed at $1645 \mathrm{~cm}^{-1}$ and $1347 \mathrm{~cm}^{-1}$ in the composite are due to N-H stretching vibrations of complexed $\mathrm{NH}_{3}$ of dopant metal complex. These peaks appear at $1618 \mathrm{~cm}^{-1}$ and $1327 \mathrm{~cm}^{-1}$ respectively in pure dopant metal complex. The observed peak at $830 \mathrm{~cm}^{-1}$ in pure dopant because of rocking vibration of $\mathrm{NH}_{3}$ molecule shifts to $888 \mathrm{~cm}^{-1}$ in PANI composite. Therefore from the discussion of FTIR of pure dopant metal complex and that of PANI composite, successful synthesis of PANI composite is proved. Also, since there occurs some shifting of PANI peaks due to the addition of metal complex, which indicates van der Waals type of interaction between them.

\subsection{XRD characterization}

The XRD data was analyzed using Powder X software. Figure $4 \mathrm{a}-\mathrm{c}$, represents the diffraction pattern of pure PANI, dopant Co complex and PANI composite with the metal complex. The peaks are indexed by characteristic Miller indices. The XRD spectrum of pure PANI shows a broad hump at $2 \theta$ value of $20^{\circ}$ which indicates its amorphous nature. The dopant metal complex shows some sharp peaks characteristic of a crystalline substance and these peaks matches well with the JCPDS -International centre for diffraction data, ICSD No 001694, page No.705-736, suggesting that the prepared metal complex is pure with monoclinic $\mathrm{C} 2 / \mathrm{m}$ (12) structure. The XRD pattern of PANI-metal complex composite resembles with that of dopant Co complex with peaks at same position or with some slight shift in their position. This indicates crystalline nature of composite. The lattice parameters calculated for the dopant metal complex after refinement are $\mathrm{a}=12.49, \mathrm{~b}=12.42$ and $\mathrm{c}$ $=21.47$ with $\alpha=\gamma=90^{\circ}$ and $\beta=112.96^{\circ}$, whereas for the PANI composite the value of various lattice parameters are $\mathrm{a}=12.50, \mathrm{~b}=12.29$ and $\mathrm{c}=21.68$ with $\alpha=\gamma=90^{\circ}$ and $\beta=113.63^{\circ}$. The different parameters of PANI and PANI composite calculated from XRD are shown in Table 1 and Table 2 respectively.

\subsection{SEM characterization}

The surface morphology of pure PANI, metal complex and PANI composite have been investigated using SEM analysis and are shown in Figure 5a-c. The SEM picture of PANI shows uniform morphology with amorphous layer like structure. The dopant metal complex shows compact morphology thereby supporting the XRD. The SEM image of PANI composite reveals that the dopant metal complex particles are dispersed in PANI matrix which also justifies the successful composite formation.

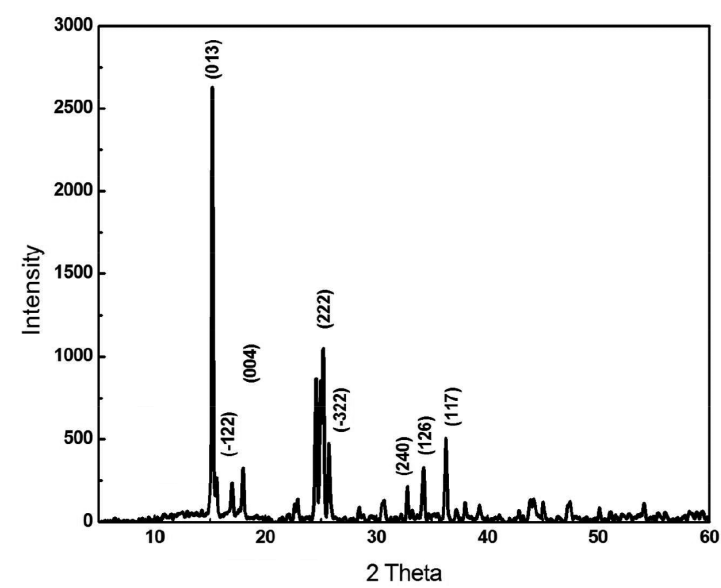

(a)

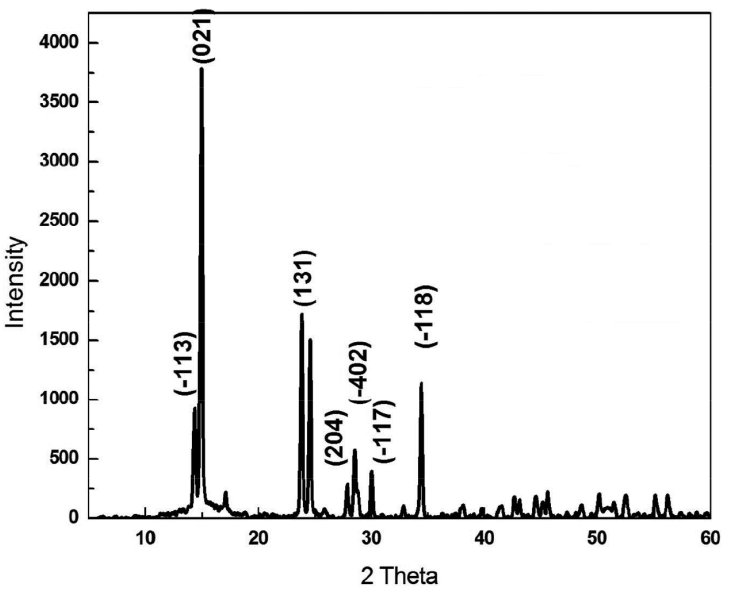

(b)

Figure 4. XRD of (a) dopant metal complex (b) PANI composite.

Table 1. Evaluated parameters from XRD data of dopant metal complex.

\begin{tabular}{|c|c|c|c|c|c|c|c|c|}
\hline $\mathbf{H}$ & $\mathbf{K}$ & $\mathbf{L}$ & $2 \theta$ (exp.) & $2 \theta$ (cal.) & $2 \theta$ (diff.) & d (exp.) & d (cal.) & Intensity \\
\hline 0 & 1 & 3 & 15.212 & 15.208 & 0.004 & 5.81964 & 5.82110 & 2638.30 \\
\hline-1 & 2 & 2 & 16.982 & 17.010 & -0.029 & 5.21705 & 5.20837 & 236.04 \\
\hline 0 & 0 & 4 & 17.963 & 17.933 & 0.029 & 4.93425 & 4.94227 & 324.79 \\
\hline 2 & 2 & 2 & 25.199 & 25.190 & 0.009 & 3.53136 & 3.53255 & 1054.90 \\
\hline-3 & 2 & 2 & 25.714 & 25.742 & -0.027 & 3.46168 & 3.45809 & 474.86 \\
\hline 2 & 4 & 0 & 32.794 & 32.752 & 0.042 & 2.72876 & 2.73213 & 214.24 \\
\hline 1 & 2 & 6 & 34.247 & 34.258 & -0.012 & 2.61624 & 2.61537 & 326.74 \\
\hline 1 & 1 & 7 & 36.267 & 36.289 & -0.022 & 2.47498 & 2.47353 & 505.72 \\
\hline
\end{tabular}


Table 2. Evaluated parameters from the XRD data of PANI composite.

\begin{tabular}{ccccccccc}
\hline $\mathbf{H}$ & $\mathbf{K}$ & $\mathbf{L}$ & $\mathbf{2 \theta}$ (ex.) & $\mathbf{2 \theta}$ (calc.) & $\mathbf{2 \theta}$ (diff.) & d (exp.) & d (calc.) & Intensity \\
\hline-1 & 1 & 3 & 14.356 & 14.343 & 0.014 & 6.16458 & 6.17044 & 926.22 \\
0 & 2 & 1 & 14.970 & 14.953 & 0.017 & 5.91316 & 5.91989 & 3784.60 \\
1 & 3 & 1 & 23.841 & 23.863 & -0.022 & 3.72922 & 3.72585 & 1721.74 \\
2 & 0 & 4 & 27.888 & 27.931 & -0.042 & 3.19659 & 3.19183 & 285.67 \\
4 & 0 & 2 & 28.540 & 28.539 & 0.001 & 3.12508 & 3.12514 & 575.38 \\
-1 & 1 & 7 & 30.038 & 30.037 & 0.001 & 2.97252 & 2.97265 & 395.37 \\
-1 & 1 & 8 & 34.438 & 34.415 & 0.024 & 2.60212 & 2.60386 & 1142.70 \\
\hline
\end{tabular}

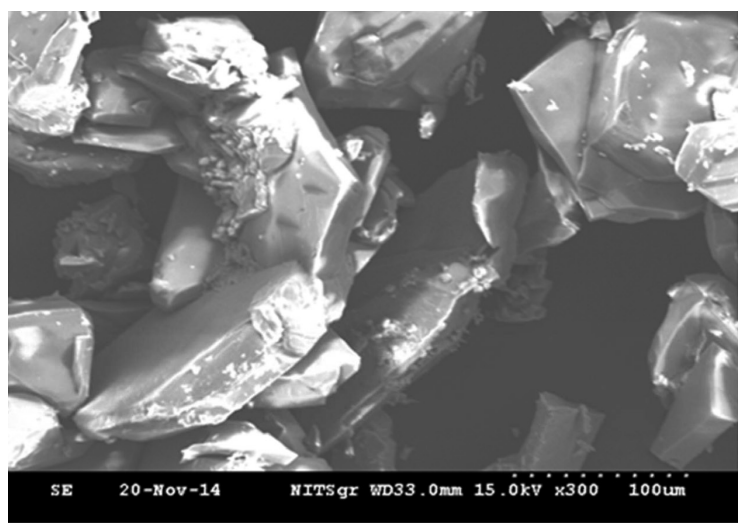

(a)

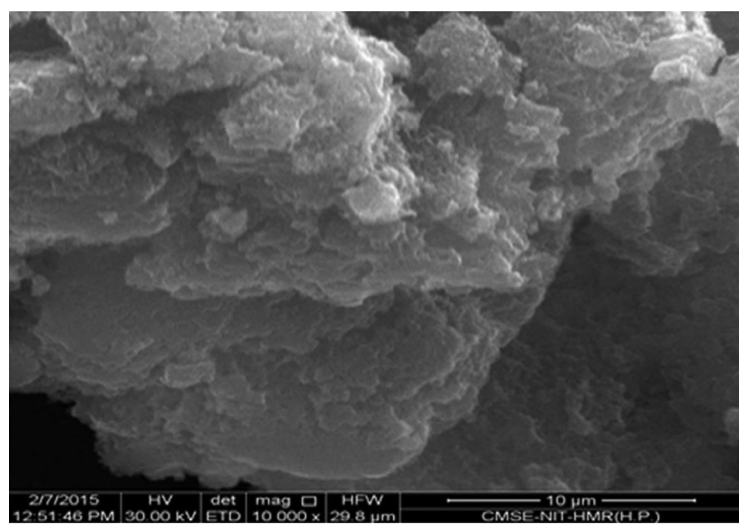

(b)

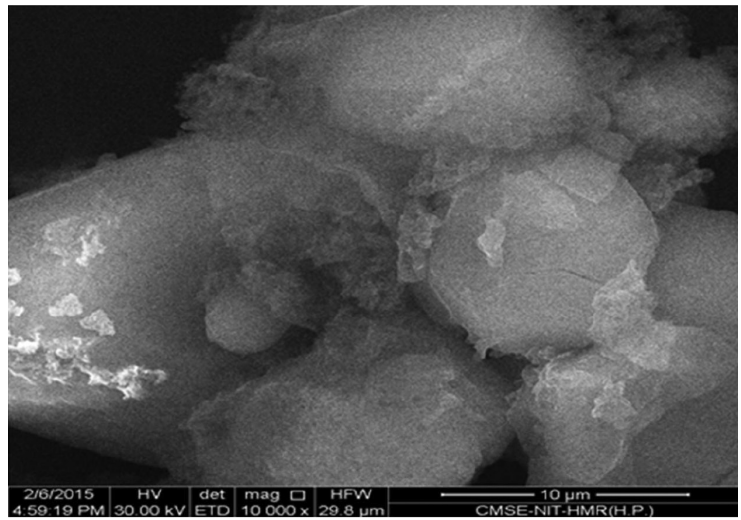

(c)

Figure 5. SEM images of (a) dopant metal complex (b) pure PANI (c) PANI composite.

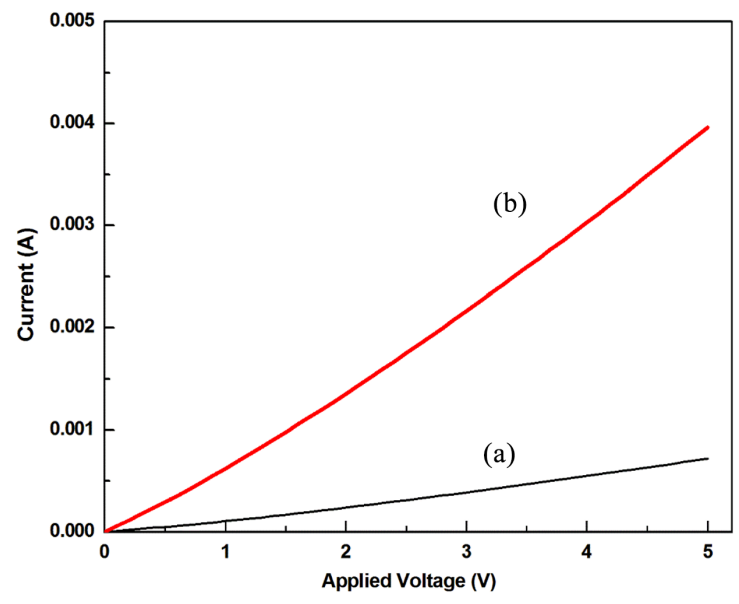

Figure 6. I-V curves of (a) pure PANI (b) PANI composite.

\subsection{Conductivity/I-V measurement}

Figure $6 \mathrm{a}, \mathrm{b}$ shows the I-V graphs of PANI and PANI composite. The polyaniline has semiconducting nature as already known, having conductance of $12 \mathrm{mS}$ (Figure 4a). In case of PANI, the conduction occurs because of the presence of some conjugational defects like polarons and bipolarons, in addition to electrons and trapped ions. However the addition of metal complex has increased its conductance by about 6 orders in magnitude to about $75 \mathrm{mS}$ (Figure 4b). The increase in conductance can be explained on the basis of generation of some additional energy levels associated with metal complex in between HOMO-LUMO energy gap thereby decreasing band gap and increase in the number of charge defects. This fact is also supported by UV-Vis spectra of PANI and PANI composite. Thus it is evident that the inserted metal complex has increased the conductance of PANI composite.

\subsection{Thermal analysis}

The TGA curve of pure PANI and PANI composite is shown in Figure 7a, b. The TG curve of PANI shows an early weight loss due to release of moisture within the layers. The curve then shows stability up to $350^{\circ} \mathrm{C}$, wherefrom it undergoes a fast decomposition of about 95-98\%, which lasts up to $600^{\circ} \mathrm{C}$. The TG of PANI doped with $\left[\mathrm{Co}\left(\mathrm{NH}_{3}\right)_{6}\right] \mathrm{Cl}_{3}$ complex shows improvement in thermal stability by about $200^{\circ} \mathrm{C}$. The thermogram shows initial 


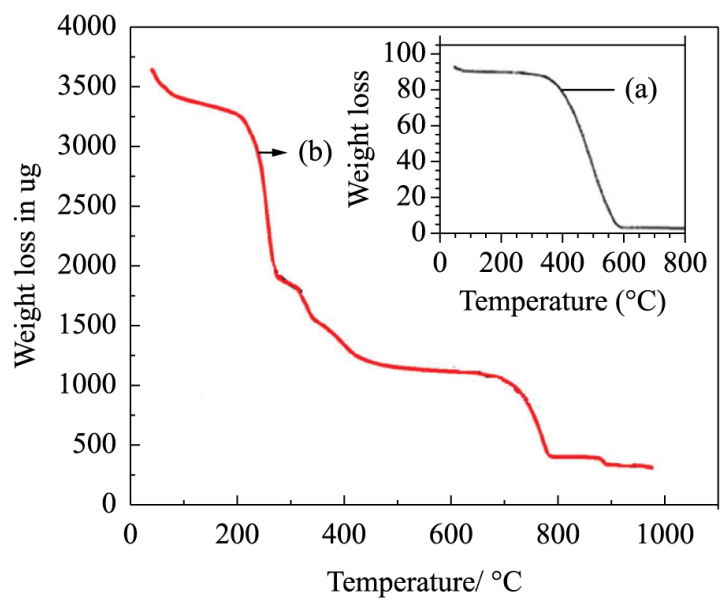

Figure 7. TGA curves of (a) pure PANI (b) PANI composite.

decomposition of $8 \%$ from ambient up to $200^{\circ} \mathrm{C}$, due to release of moisture. This decomposition leads to further continuous weight loss of $60 \%$ up to $500^{\circ} \mathrm{C}$, which may be due to loss of $\mathrm{C}, \mathrm{H}$ and $\mathrm{N}$ moieties. After $500^{\circ} \mathrm{C}$ the thermogram runs parallel to $\mathrm{X}$-axis, showing stability up to $700^{\circ} \mathrm{C}$, wherefrom it undergoes further weight loss of about $20 \%$ which may

\section{References}

1. Asim N, Radiman S and Yarmo MA. Preparation and characterization of core-shell polyaniline $/ \mathrm{V}_{2} \mathrm{O}_{5}$ nanocomposite via microemulsion method. Materials Letters. 2008; 62(6):10441047. http://dx.doi.org/10.1016/j.matlet.2007.07.051.

2. MacDiarmid AG. Synthetic metals: a novel role for organic polymers. Synthetic Metals. 2002; 125(1):11-22. http://dx.doi. org/10.1016/S0379-6779(01)00508-2.

3. Chen SA, Chuang KR, Chao CL and Lee HT. White-light emission from electroluminescence diode with polyaniline as the emitting layer. Synthetic Metals. 1996; 82(3):207-210. http://dx.doi.org/10.1016/S0379-6779(96)03790-3.

4. Heeger AJ. Semiconducting and metallic polymers: the fourth generation of polymeric materials. Synthetic Metals. 2002; 125(1):23-42. http://dx.doi.org/10.1016/S0379-6779(01)00509-4.

5. Mohan VM, Chen W and Murakami K. Synthesis, structure and electrochemical properties of polyaniline $/ \mathrm{MoO}_{3}$ nanobelt composite for lithium battery. Materials Research Bulletin. 2013; 48(2):603608. http://dx.doi.org/10.1016/j.materresbull.2012.11.041.

6. Majid K, Awasthi S and Singla ML. Low temperature sensing capability of polyaniline and $\mathrm{Mn}_{3} \mathrm{O}_{4}$ composite as NTC material. Sensors and Actuators. A, Physical. 2007; 135(1):113-118. http://dx.doi.org/10.1016/j.sna.2006.06.055.

7. Parvatikar N, Jain S, Khasim S, Revansiddappa M, Bhoraskar SV and Prasad MVNA. Electrical and humidity sensing properties of polyaniline/ $\mathrm{WO}_{3}$ composites. Sensors and Actuators. B, Chemical. 2006; 114(2):599-03. http://dx.doi.org/10.1016/j. snb.2005.06.057.

8. Sathiyanarayanan S, Syed Azim S and Venkatachari G. Preparation of polyaniline- $\mathrm{TiO}_{2}$ composite and its comparative corrosion protection performance with polyaniline. Synthetic Metals. 2007; 157(4):205-213. http://dx.doi.org/10.1016/j. synthmet.2007.01.012. be because of release of dopant moieties. The thermogram shows some amount of residue even at $800^{\circ} \mathrm{C}$, which reflects the thermal stability of PANI composite with $\left[\mathrm{Co}\left(\mathrm{NH}_{3}\right)_{6}\right]$ $\mathrm{Cl}_{3}$ have increased significantly.

\section{Conclusion}

Successful synthesis of metal complex and PANI composite with metal complex has been proved by FTIR spectra. XRD study shows crystalline structure of metal complex, which is retained by the composite. SEM images reveal dispersion of metal complex particles in PANI matrix. UV-Vis spectroscopy revealed increase in energy band gap of composite on irradiation due to distortion of polymer chains. The electrical measurement shows increase in conductance of composite as compared to PANI. Thermal analysis shows increase in the thermal stability of PANI composite by about $200^{\circ} \mathrm{C}$ than that of pure PANI. The material synthesized can be used for high temperature application purposes.

\section{Acknowledgements}

The authors are thankful to Director, Prof. Rajat Gupta for his help and support. Help and support from Dr. S A Shah, Department of Chemistry is also acknowledged.

9. Chauduri D and Sarma DD. $\mathrm{BF}_{3}$-doped polyaniline: a novel conducting polymer Pramana. Journal of Physics. 2006; 67(1):135-139.

10. Liu Y, Li Y and Schanze KS. Photophysics of $\pi$-conjugated oligomers and polymers that contain transition metal complexes. Journal of Photochemistry And photobilology C: Photochemistry Reviews. 2002; 3(1):1-23. http://dx.doi.org/10.1016/S13895567(02)00004-7.

11. Paloheimo J, Laakso K, Isotalo H and Stubb H. Conductivity, thermoelectric power and field-effect mobility in self-assembled films of polyanilines and oligoanilines. Synthetic Metals. 1995; 68(3):257. http://dx.doi.org/10.1016/0379-6779(94)02308-L.

12. Epstein AJ, Smallfield JAO, Guan H and Fahlman M. Corrosion protection of aluminum and aluminum alloys by polyanilines: A potentiodynamic and photoelectron spectroscopy study. Synthetic Metals. 1999; 102(1):1374-1376. http://dx.doi.org/10.1016/ S0379-6779(98)00383-X.

13. Fahlman M, Crispin X, Guan H, Li S, Smallfield AO, Wei $\mathrm{Y}$, et al. Polyaniline-metal interfaces: Implications on corrosion protection of steel and aluminum alloys. Polymer Prepration. 2000; 220:53.

14. Posdorfer J and Wessling B. Oxidation of copper in the presence of the organic metal polyaniline. Synthetic Metals. 2001; 119(13):363-364. http://dx.doi.org/10.1016/S0379-6779(00)01393-X.

15. Higuchi M, Ikeda I and Hirao T. A novel synthetic metal catalytic system. The Journal of Organic Chemistry. 1997; 62(4):1072-1078. http://dx.doi.org/10.1021/jo9617575.

16. Hirao T. Conjugated systems composed of transition metals and redox-active $\pi$-conjugated ligands. Coordination Chemistry Reviews. 2002; 226(1):81-91. http://dx.doi.org/10.1016/S00108545(01)00436-2.

17. Dimitriev OP, Smertenko PS, Stiller B and Brehmer L. Polyaniline-transition metal salt complexes: insight into 
formation mechanisms. Synthetic Metals. 2005; 149(2):187192. http://dx.doi.org/10.1016/j.synthmet.2004.12.007.

18. Rafiqi FA, Rather MS and Majid K. Doping polyaniline with copper bisglycinate $[\mathrm{Cu}(\mathrm{gly}) 2]$ - synthesis, characterization and thermal study. Synthetic Metals. 2013; 171:32-38. http:// dx.doi.org/10.1016/j.synthmet.2013.03.009.

19. Rafiqi FA and Majid K. Synthesis, characterization, luminescence properties and thermal studies of polyaniline and polythiophene composites with rare earth terbium (III) complex. Synthetic Metals. 2015; 202:147-156. http://dx.doi.org/10.1016/j. synthmet.2015.01.032.
20. Rather MS, Majid K, Wanchoo RK and Singla ML. Nanocomposite of polyanilinewith the photoadduct of potassium hexacyanoferrate and pyridine ligand: structural, electrical, mechanical and thermal study. Synthetic Metals. 2013; 179:60-66. http://dx.doi. org/10.1016/j.synthmet.2013.07.010.

21. Bjerrum J, McReynolds JP, Oppegard AL and Parry RW. Hexamminecobalt(III) salts. Inorganic Syntheses. 1946; 2:216221. http://dx.doi.org/10.1002/9780470132333.ch69.

22. Huang WS and MacDiarmid AG. Optical properties of polyaniline. Polymer. 1993; 34(9):1833-1845. http://dx.doi. org/10.1016/0032-3861(93)90424-9. 